

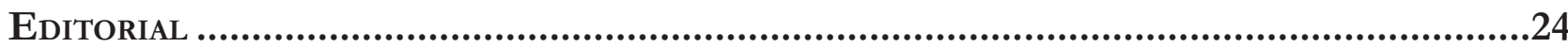

O Direito na fronteira da razão: Psicologia, neurociência e economia comportamental................... 24 Patrícia Perrone Campos Mello e Sergio Nojiri

I. NeURodireito: COGNIÇão, EMOÇÃo, JUÍZOS MORAIS E CIÊNCIA ..........................................26

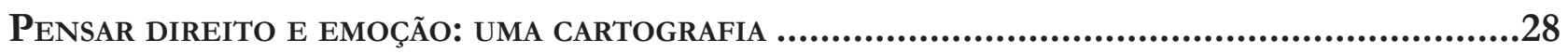

Nevita Maria Pessoa de Aquino Franca Luna

Neurodireito: o início, o fim E O MEIO

Carlos Marden e Leonardo Martins Wykrota

ENSAIO JURÍDICO SOBRE A RACIONALIDADE HUMANA: MAIORES, CAPAZES E IRRACIONAIS

André Perin Schmidt Neto e Eugênio Facchini Neto

DIVERGÊNCIAS DE PRINCÍPIO: ARGUMENTOS JURÍDICOS E MORAIS EM UM CENÁRIO DE DESACORDOS SOCIAIS

André Matos de Almeida Oliveira, Pâmela de Rezende Côrtes e Leonardo Martins Wykrota

CONSILIÊNCIA E A POSSIBILIDADE DO NEURODIREITO: DA DESCONFIANÇA À RECONCILIAÇÃO DISCIPLINAR.....

Thaís de Bessa Gontijo de Oliveira e Renato César Cardoso

MODELOS DE MORALIDADE

Molly J. Crockett

A INFELIZ BUSCA POR FELICIDADE No DiREITo

Úrsula Simões da Costa Cunha Vasconcellost, Noel Struchiner e Ivar Hannikainen

Além da liberdade: PersPeCtivas Em Nietzsche.

Lucas Costa de Oliveira

A mediaÇão de CONFlitos SOb a PERSPECTIVA do DESENVOLVIMENTO HUMANO: AS CONTRIBUIÇÕES DA PSICOLOGIA POSITIVA

Simone de Biazzi Ávila Batista da Silveira e Deise Brião Ferraz

Neuroimagiologia e aValiação de ResPonsabilidade

Nicole A. Vincent 
ANÁLISE CRÍTICA DA ORIENTAÇÃO DE CIDADÃOS COMO MÉTODO PARA OTIMIZAR DECISÕES PÚBLICAS POR MEIO DA TÉCNICA NUDGE.

Luciana Cristina Souza, Karen Tobias França Ramos e Sônia Carolina Romão Viana Perdigão

Políticas públicas e o deVer de monitoramento: “LEVANdo os Direitos A SÉrio". .252 Ana Paula de Barcellos

Nudges E POLÍticas PÚblicas: uM MECANISMO DE COMBATE AO TRABALHO EM CONDIÇÃo ANÁLOGA À DE ESCRAVO .267

Amanda Carolina Souza Silva, Débhora Renata Nunes Rodrigues e Saul Duarte Tibaldi

REDUZINDO A TRIBUTAÇÃO COGNITIVA: LIÇÕES COMPORTAMENTAIS PARA A DIMINUIÇÃO DOS EFEITOS PSICOLÓGICOS ADVERSOS DA POBREZA.............................................................288 Leandro Novais e Silva, Luiz Felipe Drummond Teixeira, Gabriel Salgueiro Soares e Otávio Augusto Andrade Santos

Políticas PÚBLICAS EM SUICÍDIO: DO PATERNALISMO CLÁSSICO AO PATERNALISMO LIBERTÁRIO E NUDGING

Davi de Paiva Costa Tangerino, Gabriel Cabral e Henrique Olive

Nudges COMO POLÍticA PÚbliCA PARA AUMENTAR O ESCASSO NÚMERO DE DOADORES DE ÓRGÃos PARA TRANSPLANTE

Roberta Marina Cioatto e Adriana de Alencar Gomes Pinheiro

Os PROGRAMAS DE INTEGRIDADE PARA CONTRATAÇÃO COM A ADMINISTRAÇÃO PÚBLICA ESTADUAL: NUDGE OU OBRIGAÇÃo LEGAL? UM OLHAR SOBRE AS DUAS PERSPECTIVAS .386

Cíntia Muniz Rebouças de Alencar Araripe e Raquel Cavalcanti Ramos Machado

Paternalismo libertário e Proteção JURídica do AMbiente: POR QUe PROTEger o AMBIENTE TAMBÉM DEVE SER PROTEGER AS LIBERDADES?

Mariana Carvalho Victor Coelho e Patryck de Araujo Ayala

Políticas PÚblicas baseadas EM EVIdÊNCIAS COMPORTAMENTAIS: REFLEXões A PARTIR do Projeto de Lei 488/2017 do Senado

Pâmela de Rezende Côrtes, André Matos de Almeida Oliveira e Fabiano Teodoro de Rezende Lara

III. ECONOMIA COMPORTAMENTAL: VIESES COGNITIVOS E POLÍTICAS PÚBLICAS .455

ECONOMIA COMPORTAMENTAL E DIREITO: A RACIONALIDADE EM MUDANÇA Marcia Carla Pereira Ribeiro e Victor Hugo Domingues

VIESES COGNITIVOS E DESENHO DE POLÍTICAS PÚBLICAS 
A neurociênCia da moralidade na tomada de DeCisões Jurídicas Complexas e No DESENHO DE POLÍTICAS PÚBLICAS

Erik Navarro Wolkart

Desvio de CARÁter ou SIMPLESMENTE HUMANO? ECONOMIA COMPORTAMENTAL APLICADA AO COMPORTAMENTO DESONESTO

Diana Orghian, Gabriel Cabral, André Pinto e Alessandra Fontana

Políticas Públicas e a ConcretizaÇão de direitos sociais: TOMAdA DE DECisão, ARQUITETURA DE ESCOLHAS E EFETIVIDADE

Ana Elizabeth Neirão Reymão e Ricardo dos Santos Caçapietra

BEHAVIORAL ECONOMICS E DIREITO DO CONSUMIDOR: NOVAS PERSPECTIVAS PARA O ENFRENTAMENTO DO SUPERENDIVIDAMENTO .568

Samir Alves Daura

A EDUCAÇÃo FORMAL PARA O CONSUMO É GARANTIA PARA UMA PRESENÇA REFLETIDA DO CONSUMIDOR NO MERCADO? UMA ANÁLISE COM BASE NA BEHAVIORAL LAW AND ECONOMICS (ECONOMIA COMPORTAMENTAL) 600

Marcia Carla Pereira Ribeiro e Edson Mitsuo Tiujo

LIBET, DETERMINISMO E CONSUMO: AS INFLUÊNCIAS DO MARKETING E A RELEVÂNCIA DA DELIBERAÇÃo CONSCIENTE NA SUPERAÇÃo CONDICIONAL DE HÁBITOS DE CONSUMO PERIGOSOS616 Émilien Vilas Boas Reis e Leonardo Cordeiro de Gusmão

CiÊNCIA DO DIREITO TRIBUTÁRIO, ECONOMIA COMPORTAMENTAL E EXTRAFISCALIDADE. .640 Hugo de Brito Machado Segundo

IV. CoMportamento JUdiCiAL: INFLUÊNCIA DE FATORES EXTRAJURÍDicos .660

FATORES METAPROCESSUAIS E SUAS INFLUÊNCIAS PARA A FORMAÇÃo DA DECISÃo JUDICIAL .662 Rogério Roberto Gonçalves de Abreu, Lúcio Grassi de Gouveia e Virgínia Colares

“A VIDA COMO ELA É": COMPORTAMENTO ESTRATÉGICO NAS CORTES Patrícia Perrone Campos Mello

A COMPOSIÇÃo do ÓRGão COLEGIAdo E SEUS EFEITOS NA TOMADA DE DECISÃo .720 André Garcia Leão Reis Valadares

Das 11 ilhas ao centro do arquipélago: os superpoderes do Presidente do STF DURANTE O RECESSO JUDICIAL E FÉRIAS .741 José Mário Wanderley Gomes Neto e Flávia Danielle Santiago Lima 
RAZÃo, EMOÇÃo E DELIBERAÇÃO: AS ADEQUAÇÕES REgIMENTAIS do SUPERIOR TribUNAL DE JUSTIÇA PARA A FORMAÇÃo DE PRECEDENTES EFICAZES

Peter Panutto e Lana Olivi Chaim

Heurística de ancoragem e fiXaÇÃo de danos morais em JUizados especiais Cíveis no Rio DE JANEIRO: UMA NOVA ANÁLISE 778

Fernando Leal e Leandro Molhano Ribeiro

LA PROTECCIÓN DE LOS DERECHOS POLÍTICOS FRENTE A LAS FUNCIONES DISCIPLINARIAS DE LAS AUTORIDADES ADMINISTRATIVAS: SUBSIDIARIEDAD Y DEFERENCIA EN EL SISTEMA INTERAMERICANO DE DERECHOS HUMANOS Jorge Ernesto Roa Roa

V. A influênCia do gÊNERo no PROCESSO DECisório JUdiCial

Como os Juízes decidem os Casos de estupro? ANALISANDo SENTENÇAS SOb A PERSPECTIVA DE VIESES E ESTEREÓTIPOS DE GÊNERO 826 Gabriela Perissinotto de Almeida e Sérgio Nojiri

GÊNERO E COMPORTAMENTO JUDICIAL NO SUPREMO TRIBUNAL FEDERAL: OS MINISTROS CONFIAM MENOS EM RELATORAS MULHERES?

Juliana Cesario Alvim Gomes, Rafaela Nogueira e Diego Werneck Arguelhes

Hércules, Hermes e a Pequena Sereia: uma reflexão sobre estereótipos de gênero, SUBPRESENTAÇÃo DAS MULHERES NOS TRIBUNAIS E (I)LEGITIMIDADE DEMOCRÁTICA DO PODER JUDICIÁRIO. .878 Jane Reis Gonçalves Pereira e Renan Medeiros de Oliveira

Prisão Cautelar de gestantes: análise do Fundamento filosófico da decisão do Habeas CoRpus N. 143.641 912

Artur César Souza e Giovania Tatibana de Souza

VI. Neurodireito APlicado ao direito E Ao Processo PENAL....................................926

CÉREbros QUe PUNEM: UMA REVISÃo CRÍTICA DA NEURoCIÊNCIA DA PUNIÇÃo .....................928 Ricardo de Lins e Horta

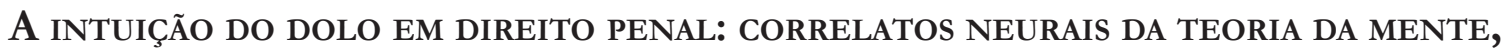
RACIOCÍNIO INDUTIVO E A GARANTIA DA CONVICÇÃO JUSTIFICADA. .946 Thiago Dias de Matos Diniz e Renato César Cardoso

As COMUNIDADES EPISTÊMICAS PENAIS E A PRODUÇÃo LEGISLATIVA EM MATÉRIA CRIMINAL..... 961 Stéphane Enguéléguélé 
DELINQUÊNCIA JUVENIL: RELAÇÕES ENTRE DESENVOLVIMENTO, FUNÇÕES EXECUTIVAS E COMPORTAMENTO SOCIAL NA ADOLESCÊNCIA .

André Vilela Komatsu, Rafaelle CS Costa e Marina Rezende Bazon

Límites TEMPORALES A LAS PENAS PRIVATIVAS DE LIBERTAD ATENDIENDO AL DESARROLLO PSICOSOCIAL.

Silvio Cuneo Nash

NEURolaw E AS PERSPECTIVAS PARA UMA ANÁLISE OBJETIVA DO COMPORTAMENTO SUGESTIONADO: REPERCUSSÃO DAS FALSAS MEMÓRIAS NA ESFERA PENAL

Mariana Dionísio de Andrade, Marina Andrade Cartaxo e Rafael Gonçalves Mota

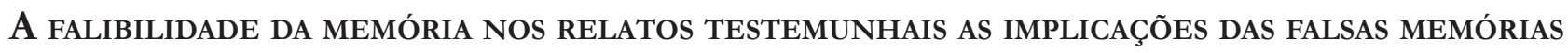
NO CONTEXTO DOS CRIMES CONTRA A DIGNIDADE SEXUAL

Caroline Navas Viana

A (IR)REPETIBILIDADE dA PROVA PENAL DEPENDENTE DA MEMÓRIA: UMA DisCUSSÃo COM BASE NA PSICOLOGIA DO TESTEMUNHO. 1058

William Weber Cecconello, Gustavo Noronha de Avila e Lilian Milnitsky Stein 


\title{
Nudges como política pública para aumentar o escasso número de doadores de órgãos para transplante*
}

\author{
Nudges as a public policy to increase \\ the scarce number of organ donors for \\ transplantation
}

\author{
Roberta Marina Cioatto** \\ Adriana de Alencar Gomes Pinheiro ${ }^{* * * * * *}$
}

* Recebido em 26/05/2018 Aprovado em 13/07/2018

** Mestre em Direito com ênfase em Direitos Sociais e Políticas Públicas de Inclusão Social pela Universidade de Santa Cruz do Sul (Unisc/ Brasil) e Mestre em Direito das Autarquias Locais pela Universidade do Minho (Uminho/ Portugal) - regime de dupla titulação. Bacharel em Direito e em Ciências Econômicas pela Universidade de Caxias do Sul (UCS/Brasil). Bolsista do XIII Curso de Introducción a la Ética de la Investigación en Seres Humanos Programa de Educación Permanente en Bioética de la Redbioética Unesco. Professora da Faculdade Paraíso do Ceará. E-mail: roberta. cioatto@fapce.edu.br.

*** Doutora e Mestre em Psicologia pela Universidade de Fortaleza (Unifor/Brasil). Membro da Associação Bras. de Ens. de Psicologia - ABEP e Associação Nacional de Pesquisa e Pós-Graduação em Psicologia - ANPEPP. Professora e Coordenadora do Curso de Psicologia da Faculdade Paraíso do Ceará. E-mail: adriana. alencae@fapce.edu.br

**** Este artigo é o terceiro de uma série de estudos que vêm sendo realizados no Núcleo de Estudos e Pesquisas em Subjetividades, Bioética e Políticas Públicas. Projeto: Bioética, Direito e Políticas Públicas. O primeiro, sobre a atualidade da retomada das discussões a respeito dos transplantes e, o segundo, contrastando números e políticas públicas adotadas pelos doze países com maior quantidade de transplantações, sugerindo a necessidade de estudos para elaboração de políticas públicas específicas de incremento nas doações para transplantes.

\section{Resumo}

Existe uma escassez de órgãos humanos para transplantes. O objetivo deste artigo é analisar a utilização de nudges como política pública para aumentar o escasso número de doadores. Primeiro, expõe-se a problemática em um contexto mundial e, mais especificamente, no Brasil. Em seguida, explana-se a noção de nudges relacionando-se sua definição com os sistemas de consentimento para doação. Por fim, conceituam-se políticas públicas. Trata-se de uma pesquisa bibliográfica, descritiva, e, de certo modo, aplicada. Quanto aos dados quantitativos, mesmo que a título de ilustração, a pesquisa foi limitada no acesso a informações disponíveis online sobre transplantes e, no que pertine à fundamentação teórica, à dificuldade de aquisição de literatura a respeito. Como resultado, sugere-se — dentre outras "cutucadas" - a implantação da doação presumida de órgãos como forma de incrementar o número de doadores. Como consequência, conclui-se que nudges podem ser utilizados como política pública para aumentar o número de doadores de órgãos para transplantes. Com o presente artigo pretende-se contribuir para a discussão sobre a implementação de políticas públicas para o aumento do número de doadores de órgãos para transplantação. Portanto, seu resultado tem implicações práticas, sociais e econômicas, uma vez que os transplantes salvam vidas além de reduzir o custo com saúde. Certamente, não se esgotou a matéria. Estudos semelhantes são exigidos à medida que a população envelhece e a pressão por ampliar a oferta intensifica-se. $\mathrm{O}$ artigo é original, e é o terceiro de uma série de estudos que vêm sendo realizados no grupo de pesquisa.

Palavras-chave: Nudges. Políticas públicas. Doadores de órgãos.

\section{Abstract}

There is a shortage of human organs for transplants. The purpose of this article is to analyze the use of nudges as a public policy to increase the scarce number of donors. First, the problem is exposed in a world context and, more specifically, in Brazil. Next, the notion of nudges is explained, re- 
lating its definition with the consent systems for donation. Finally, public policies are conceptualized. It is a bibliographical research, descriptive, and, in a way, applied. As for the quantitative data, even for illustration purposes, the research was limited in the access to information available on transplants online and, as far as the theoretical basis is concerned, the difficulty of acquiring literature about. As a result, it is suggested - among other nudges - the implantation of organs presumed donation in order to increase the number of donors. As a consequence, it can be concluded that nudges can be used as public policy to increase the number of organ donors for transplants. The present article intends to contribute to the discussion about the implementation of public policies for the increase in the number of donors of organs for transplantation. Therefore, its outcome has practical, social and economic implications, since transplants save lives and reduce health costs. Certainly, the matter has not been exhausted. Similar studies are required as the population ages and the pressure to expand supply intensifies. The article is original and is the third in a series of studies that have been conducted in the research group.

Keywords: Nudges. Public policies. Organ donors.

\section{INTRODUÇÃo}

Existe uma escassez de órgãos humanos para transplantes, porque os órgãos somente podem ser extraídos, de pessoa falecida, após o diagnóstico de morte encefálica, inobstante alguns países permitam a extração também diante do critério de morte cardiocirculatória.

Ocorre que as causas mais comuns de morte encefálica, a conhecida morte cerebral, são traumatismo cranioencefálico e acidente vascular encefálico - fatos que representam uma restrição para o processo de transplantação, uma vez que acontecem em uma pequena parcela das mortes. Em 2015, segundo dados do Registro Brasileiro de Transplantes coletados no IBGE, em relação a 1.264.175 mortes declaradas no país, 34.721 foram de causas neurológicas.

Outrossim, muitos familiares, diante dessa situação, não permitiram e não permitem a extração de órgãos do potencial doador. Como consequência, muitas são as vidas interrompidas pela escassez de órgãos para transplantação.

Tais ocorrências, somadas ao estilo de vida e ao aumento da expectativa de vida da população, fazem com que a demanda por doadores de órgãos seja cada vez maior. ${ }^{1}$ Essa insuficiência exige incessantes esforços para aumentar a oferta, sendo preciso o impulsionamento de políticas públicas a fim de atender ao maior número possível de enfermos, pois o transplante é a melhor — senão a única — solução para o paciente na quase totalidade dos casos.

E o transplante, também, é a melhor resposta para a sociedade em relação a gastos com saúde em comparação com as alternativas, representando uma economia com diálises e medicamentos, além do retorno do indivíduo ao mercado de trabalho.

Na primeira seção deste trabalho, expõe-se a problemática da escassez de órgãos humanos para transplantes em um contexto mundial e, mais especificamente, no Brasil. Em seguida, a noção de nudges é apresentada e relaciona-se sua definição com os sistemas de consentimento para doação de órgãos para transplantação. Por fim, conceituam-se políticas públicas.

Os dados quantitativos, mesmo que a título de ilustração, foram obtidos principalmente consultando-se as fontes conhecidas disponíveis online, dentre as quais o Registro Brasileiro de Transplantes da Associação Brasileira de Transplante de Órgãos.

1 A maioria dos novos casos de insuficiência renal é resultado de pressão alta ou diabetes; ter mais de 60 anos e ter histórico familiar de insuficiência também aumentam o risco de doença renal. 
No que pertine à fundamentação teórica, tomaram-se como referência Cass Sunstein e Richard Thaler, Nobel de Economia de 2017. Expoentes no assunto, esses autores exploram as consequências da racionalidade nos processos de tomada de decisão — a chamada economia comportamental.

Trata-se de uma pesquisa bibliográfica, descritiva, e, de certo modo, aplicada, pois pretende-se contribuir para a discussão sobre a implementação de políticas públicas para o aumento do número de doadores de órgãos para transplantação.

\section{UMA BREVE CONTEXTUALIZAÇÃO SOBRE DOAÇÕES DE ÓRGÃOS E TRANSPLANTES}

Os Estados Unidos da América são o principal país na realização de transplantes de órgãos humanos e, inobstante ostentem o primeiro lugar na lista de números absolutos de transplantes realizados, aproximadamente 120.000 pessoas permanecem em listas de espera no país. Destas, quase 8.000 não viverão para receber o órgão, uma média de 20 pessoas falecidas por dia no aguardo por um transplante. ${ }^{2}$ Sua taxa de doadores efetivos de órgãos por milhão de população é 31, $0,{ }^{3}$ superior ao dobro do índice do Brasil, mas mais de 10 pontos a menos que a Espanha, primeira colocada em doadores por milhão de população.

$\mathrm{Na}$ China, menos de 1\% da população que necessita de um transplante o recebe, em comparação com cerca de $20 \%$ nos Estados Unidos. ${ }^{4}$

Na França, em 2015, 571 pessoas escolheram doar enquanto vivos, 21.000 esperaram por um transplante e 553 morreram enquanto na lista de espera por um órgão. ${ }^{5}$

A Espanha, oitava colocada em números absolutos de transplantes, ostenta, há 26 anos, o recorde mundial de doadores de órgãos falecidos por milhão de habitantes: 43,4 em $2016^{6}$ e 46,9 em $2017^{7}$. Seu sistema é referência mundial; mesmo assim, não existem órgãos para todos os que deles precisam.

Na Alemanha, menos de 800 pessoas foram doadoras em 2017, e cerca de 10 mil pessoas estão no aguardo de um órgão no país. Em média, 3 pacientes da lista de espera morrem todos os dias. ${ }^{8}$ Nesse mesmo ano, o número de doadores de órgãos atingiu a maior baixa de todos os tempos: 9,3 por milhão de população. ${ }^{9}$

2 OSSOLA, Alexandra. Crisis in America: medical experts use new tech tools to combat the organ transplant shortage. CNBC, 21 jun. 2017. Disponível em: < https://www.cnbc.com/2017/06/20/medical-experts-use-new-tech-tools-to-combat-organ-transplant-shortage.html>. Acesso em: 24 mar. 2018.

3 ASSOCIAÇÃO BRASILEIRA DE TRANSPLANTE DE ÓRGÃOS. Dimensionamento dos Transplantes no Brasil e em cada estado (2010-2017). Registro Brasileiro de Transplantes, São Paulo, ano 23, n. 4, jan./dez. 2017. Disponível em: <http://www.abto.org. $\mathrm{br} /$ abtov03 $/$ default.aspx?mn $=515 \& \mathrm{c}=900 \& \mathrm{~s}=0 \&$ friendly $=$ registro-brasileiro-de-transplantes-estatistica-de-transplantes $>$. Acesso em: 7 nov. 2017.

4 CHINA to cease prisoner organ transplants. DW, 04 dez. 2014. Disponível em: <http://www.dw.com/en/china-to-cease-prisoner-organ-transplants/a-18109346>. Acesso em: 10 fev. 2018; FAN, Jiayang. Can China stop organ trafficking? The New Yorker, 10 jan. 2014. Disponível em: <http://www.newyorker.com/news/news-desk/can-china-stop-organ-trafficking>. Acesso em: 1 maio 2017.

5 A PARTIR DU 1er janvier, tous les Français seront donneurs d'organes par défaut. Lexpress, 29 dec. 2016. Disponível em: < https:// www.lexpress.fr/actualite/societe/sante/a-partir-du-1er-janvier-tous-les-francais-seront-donneurs-d-organes-par-defaut_1864325. html?utm_campaign=Echobox\&utm_medium =Social\&utm_source $=$ Facebook\&link_time $=1483015812 \# x$ tor $=$ CS3-5076>. Acesso em: 7 maio 2018.

6 ESPANHA é campeã do mundo em doações de órgãos. Exame, 17 abr. 2017. Disponível em: <https://exame.abril.com.br/ ciencia/espanha-e-campea-do-mundo-em-doacoes-de-orgaos/>. Acesso em: 13 nov. 2017.

7 EL ÉXITO de los transplantes. El País, 12 ene. 2018. Disponível em: <https://elpais.com/elpais/2018/01/12/opinion/1515782432_390027.html?id_externo_rsoc=TW_CC\&utm_content $=$ buffer2c070\&utm_medium =social\&utm_ source $=$ facebook.com\&utm_campaign=buffer $>$. Acesso em: 10 fev. 2018.

8 WER NICHT widerspricht, wird Organspender. Süddeutsche Zeitung, Munique, 13 feb. 2018. Disponível em: < http://www.sueddeutsche.de/politik/niederlande-wer-nicht-widerspricht-wird-organspender-1.3866596>. Acesso em: 27 mar. 2018.

9 GERMAN patients turn to Croatia for organ donations. DW, 29 jan. 2018. Disponível em: < http://www.dw.com/en/germanpatients-turn-to-croatia-for-organ-donations/a-42357468>. Acesso em: 24 mar. 2018. 
No Brasil, o terceiro país que mais faz transplantes no mundo, a média de doadores efetivos por milhão de população, em 2016, foi 14,6 - a vigésima oitava posição. Em 2017, 32.402 pacientes permaneciam em listas de espera, 1.689 faleceram aguardando e 2.740 doações deixaram de ser concretizadas diante da recusa expressada pelos familiares do potencial doador. O país não superou os 16,6 doadores efetivos por milhão de população, mas ultrapassou, consideravelmente, os 9,9 em 2010. Santa Catarina e Paraná são os estados brasileiros que ultrapassaram os 30 doadores por milhão de população, com índices de 40,8 e 38,0, superando os Estados Unidos e aproximando-se das melhores taxas mundiais. Em 2017, segundo dados do Registro Brasileiro de Transplantes coletados no IBGE, em relação a 10.629 potenciais doadores brasileiros, somente 3.415 tornaram-se doadores efetivos. ${ }^{10}$

Isso quer dizer que a taxa de doadores efetivos por milhão de população saltaria de 16,6 para 51,6 se não houvesse recusas.

\section{NUDGES}

Em 2008, Cass Sunstein e Richard Thaler, vencedor do Nobel de Economia de 2017, publicaram um trabalho nominado Nudges. Para eles, aspectos "aparentemente insignificantes do ambiente em que as decisões são tomadas podem ter um impacto substancial no comportamento das pessoas" (tradução nossa). ${ }^{11}$

Em contextos que variam, nudges referem-se a maneiras de aplicar "toques" para resolver problemas sociais. ${ }^{12}$ Uma espécie de pequeno "empurrão" ou leve "cutucada" que incentiva ou altera determinada escolha individual. $\mathrm{O}$ uso de insights comportamentais como política pública.

Nudges são sutis mudanças de política que incentivam pessoas a tomarem decisões de interesse próprio e no melhor interesse de todos; orientam o comportamento dos indivíduos de uma maneira previsível, sem proibir quaisquer opções. Nudges significam "intervenções e políticas que dependem da ciência comportamental para orientar as pessoas em uma direção específica" (tradução nossa), ${ }^{13}$ sem desconsiderar sua liberdade de escolha.

Baseiam-se em insights da ciência comportamental e, quando usados eticamente, podem ser muito úteis. Assim, um nudge não pode ser empregado para convencer pessoas a tomar decisões das quais se arrependerão mais tarde — nesse caso, tratar-se-ia de phishing ou de um bad nudge. ${ }^{14}$

Os nudges compartilham características: não afetam os incentivos econômicos das pessoas; são centrados no ser humano; são voluntários, preservam a liberdade de escolha; são transparentes e não enganosos.

Três princípios devem orientar o uso de nudges, segundo Richard Thaler:

Todas as cutucadas devem ser transparentes e nunca enganosas. [...] Deve haver boas razões para

10 ASSOCIAÇÃO BRASILEIRA DE TRANSPLANTE DE ÓRGÃOS. Dimensionamento dos Transplantes no Brasil e em cada estado (2010-2017). Registro Brasileiro de Transplantes, São Paulo, ano 23, n. 4, jan./dez. 2017. Disponível em: <http://www.abto. org.br $/$ abtov03 $/$ default.aspx?mn $=515 \& \mathrm{c}=900 \& \mathrm{~s}=0 \&$ friendly $=$ registro-brasileiro-de-transplantes-estatistica-de-transplantes $>$. Acesso em: 7 nov. 2017.

11 TAMS, Carten. Small is beautiful: using gentle nudges to change organizations. Forbes, 22 feb. 2018. Disponível em: < https://www. forbes.com/sites/carstentams/2018/02/22/small-is-beautiful-using-gentle-nudges-to-change-organizations/\#6fc50c8e5a8d $>$. Acesso em: 5 maio 2018.

12 CHU, Ben. What is 'nudge theory' and why should we care? Explaining Richard Thaler's Nobel economics prize-winning concept. Independent, 9 oct. 2017. Disponível em: < https://www.independent.co.uk/news/business/analysis-and-features/nudge-theory-richard-thaler-meaning-explanation-what-is-it-nobel-economics-prize-winner-2017-a7990461.html>. Acesso em: 5 maio 2018. 13 THALER, Richard H. et al. Governments are trying to nudge us into better behaviour: is it working? The Washington Post, 11 aug. 2017. Disponível em: <https://www.washingtonpost.com/news/wonk/wp/2017/08/11/governments-are-trying-to-nudgeus-into-better-behavior-is-it-working/?noredirect=on\&utm_term $=.104 \mathrm{c} 8 \mathrm{ff} 2655 \mathrm{a}>$. Acesso em: 5 maio 2018.

14 Robert Shiller e George Akerlof, ambos economistas ganhadores do Nobel, que escreveram um livro sobre o assunto, Phishing for Phools. 
acreditar que o comportamento que está sendo encorajado melhorará o bem-estar daqueles que estão sendo cutucados. (Tradução nossa) $)^{15}$

Esse recurso não infringe as liberdades civis nem pode ser criticado como paternalista, uma vez que "a opção de não participação permanece sempre disponível para as pessoas". (tradução nossa). ${ }^{16}$

Barack Obama, quando presidente do país, "recrutou Cass Sunstein como consultor e exortou os departamentos do governo dos EUA a adotarem conceitos econômicos comportamentais. Em 2010, o governo do Reino Unido criou uma Equipe de Insights Comportamentais" para desenvolver políticas públicas. (Tradução nossa $)^{17}$.

Em diferentes áreas, os nudges têm um impacto financeiro muito mais representativo do que políticas tradicionais, como subsídios, impostos e educação. Observe-se o caso de vacinas — o tratamento médico preventivo, talvez, mais eficaz. Dados mostraram que, quando solicitados a planificar sobre quando receberiam a vacina contra a gripe, americanos aumentaram as taxas de vacinação em 4,2\%. O resultado apresentou-se cerca de 1,5 vez mais rentável que outras abordagens, como pagar a estudantes para vacinarem-se, ou campanhas educacionais sobre os benefícios da vacinação. ${ }^{18}$

No Reino Unido, para que quitassem seus impostos com pontualidade, "as pessoas recebiam uma carta dizendo que a maioria dos contribuintes pagava seus impostos a tempo, o que teve resultados muito positivos." (Tradução nossa) ${ }^{19}$.

Em 2012, com o intuito de aumentar as baixas taxas de poupança previdenciária entre os trabalhadores do setor privado, o mesmo Reino Unido determinou que os empregadores estabelecessem uma espécie de inscrição automática: os funcionários estariam automaticamente inscritos e as contribuições seriam deduzidas de sua remuneração, a menos que, formalmente, solicitassem a isenção. "A teoria era que muitas pessoas realmente queriam reservar mais dinheiro para a aposentadoria, mas teriam sido impedidas de fazê-lo pela necessidade de tomar o que elas temiam ser decisões complicadas." Assim, tal forma de inscrição facilitaria "o que eles realmente queriam fazer", aumentando as taxas de poupança. Como resultado, a participação ativa em esquemas de pensão do setor privado saltou de 2,7 milhões em 2012 para 7,7 milhões em 2016. (Tradução nossa) $)^{20}$.

No Brasil, o art. $4^{\circ}$ da Lei Federal no $13.183 / 2015$, que acresce parágrafos ao artigo $1^{\circ}$ da Lei $n^{\circ}$ 12.618/2012, também criou a adesão automática do servidor público federal titular de cargo efetivo a fundos de previdência complementar:

$\S 2^{\circ}$ Os servidores e os membros referidos no caput deste artigo com remuneração superior ao limite máximo estabelecido para os benefícios do Regime Geral de Previdência Social, que venham a ingressar no serviço público a partir do início da vigência do regime de previdência complementar de que trata esta Lei, serão automaticamente inscritos no respectivo plano de previdência complementar desde a data

15 THALER, Richard H. The power of nudges, for good and bad. The New York Times, 31 oct. 2015. Disponível em: < https:// www.nytimes.com/2015/11/01/upshot/the-power-of-nudges-for-good-and-bad.html>. Acesso em: 5 maio 2018.

$16 \mathrm{CHU}, \mathrm{Ben}$. What is 'nudge theory' and why should we care? Explaining Richard Thaler's Nobel economics prize-winning concept. Independent, 9 oct. 2017. Disponível em: <https://www.independent.co.uk/news/business/analysis-and-features/nudge-theory-richard-thaler-meaning-explanation-what-is-it-nobel-economics-prize-winner-2017-a7990461.html>. Acesso em: 5 maio 2018. $17 \mathrm{CHU}$, Ben. What is 'nudge theory' and why should we care? Explaining Richard Thaler's Nobel economics prize-winning concept. Independent, 9 oct. 2017. Disponível em: <https://www.independent.co.uk/news/business/analysis-and-features/nudge-theory-richard-thaler-meaning-explanation-what-is-it-nobel-economics-prize-winner-2017-a7990461.html>. Acesso em: 5 maio 2018. 18 THALER, Richard H. et al. Governments are trying to nudge us into better behaviour: is it working? The Washington Post, 11 aug. 2017. Disponível em: <https://www.washingtonpost.com/news/wonk/wp/2017/08/11/governments-are-trying-to-nudgeus-into-better-behavior-is-it-working/?noredirect=on\&utm_term $=.104 \mathrm{c} 8 \mathrm{ff} 2655 \mathrm{a}>$. Acesso em: 5 maio 2018.

19 KEATING, Sarah. The nation that thrived by nudging its population. BBC, 20 feb. 2018. Disponível em: <http://www.bbc. com/future/story/20180220-the-nation-that-thrived-by-nudging-its-population>. Acesso em: 5 maio 2018.

$20 \mathrm{CHU}, \mathrm{Ben}$. What is 'nudge theory' and why should we care? Explaining Richard Thaler's Nobel economics prize-winning concept. Independent, 9 oct. 2017. Disponível em: <https://www.independent.co.uk/news/business/analysis-and-features/nudge-theory-richard-thaler-meaning-explanation-what-is-it-nobel-economics-prize-winner-2017-a7990461.html>. Acesso em: 5 maio 2018. 
de entrada em exercício.

$\int 3^{\circ}$ Fica assegurado ao participante o direito de requerer, a qualquer tempo, o cancelamento de sua inscrição, nos termos do regulamento do plano de benefícios.

$\int 4^{\circ} \mathrm{Na}$ hipótese do cancelamento ser requerido no prazo de até noventa dias da data da inscrição, fica assegurado o direito à restituição integral das contribuições vertidas, a ser paga em até sessenta dias do pedido de cancelamento, corrigidas monetariamente.

$\int 5^{\circ} \mathrm{O}$ cancelamento da inscrição previsto no $\int 4^{\circ}$ não constitui resgate.

$\int 6^{\circ} \mathrm{A}$ contribuição aportada pelo patrocinador será devolvida à respectiva fonte pagadora no mesmo prazo da devolução da contribuição aportada pelo participante.

Inobstante, tramita, no Supremo Tribunal Federal, a Ação Direta de Inconstitucionalidade - ADI no 5.502/DF, que questiona a constitucionalidade dessa adesão automática.

Outros exemplos podem ser elencados, tais como a inscrição automática em energia verde, com a capacidade de recusar; um aviso de que uma fatura está vencendo; o envio de correspondência a famílias comparando seu consumo de energia com o de seus vizinhos. "Quando equiparado com oferecer um desconto aos clientes de serviços públicos se eles reduzissem o consumo de energia, o nudge mostrou-se oito vezes mais econômico." 21

Em São Paulo, escolas públicas estaduais usaram a teoria para reduzir a evasão: lembretes via SMS foram remetidos aos pais sobre a importância da frequência escolar. ${ }^{22}$

Em Cingapura, campanhas públicas foram estabelecidas a fim de criar um senso de identidade social em uma população multicultural. Keep Singapore Clean e Plant Trees eram slogans sobre melhorar a limpeza e o meio ambiente. Outras campanhas incentivaram as pessoas a falar mandarim para criar uma sociedade mais coesa, cortês e atenciosa. Mas o país se move em direção a uma abordagem mais sutil de influenciar os comportamentos de seus habitantes. ${ }^{23}$

Um centro médico no Qatar "conseguiu aumentar a aceitação do rastreio de diabetes, oferecendo-se para testar as pessoas durante o Ramadã. As pessoas estavam em jejum de qualquer maneira, então, o incômodo de não comer antes do teste estava removido. Era conveniente e oportuno". ${ }^{24}$ (Tradução nossa).

Outros nudges são ainda mais simples: academias ao ar livre foram construídas próximas das entradas dos prédios, de modo que são fáceis de usar e de serem lembradas constantemente. "Estações de trem têm setas verdes e vermelhas na plataforma indicando onde você deve ficar de modo a acelerar o processo de desembarque." (Tradução nossa). Islândia, Índia e China testaram ilusões de ótica 3D que fazem as passagens em cruzamentos parecer estarem flutuando acima do solo, projetadas para estimular os motoristas a desacelerarem. ${ }^{25}$

Essas técnicas de nudges apresentam-se de muitas formas, mas é o estabelecimento de regras padrão o que interessa para o presente trabalho.

21 THALER, Richard H. et al. Governments are trying to nudge us into better behaviour: is it working? The Washington Post, 11 aug. 2017. Disponível em: <https://www.washingtonpost.com/news/wonk/wp/2017/08/11/governments-are-trying-to-nudgeus-into-better-behavior-is-it-working/?noredirect=on\&utm_term=.104c8ff2655a >. Acesso em: 5 maio 2018.

22 FRAGA, Érica; PINTO, Ana Estela de Sousa. Escolas públicas de São Paulo usam teorias de Nobel para reduzir evasão. Folha de São Paulo, 15 out. 2017. Disponível em: <http://www1.folha.uol.com.br/mercado/2017/10/1927050-escolas-publicas-de-saopaulo-usam-teorias-de-nobel-para-reduzir-evasao.shtml>. Acesso em: 5 maio 2018.

23 KEATING, Sarah. The nation that thrived by nudging its population. BBC, 20 feb. 2018. Disponível em: <http://www.bbc. com/future/story/20180220-the-nation-that-thrived-by-nudging-its-population>. Acesso em: 5 maio 2018.

24 KEATING, Sarah. The nation that thrived by nudging its population. BBC, 20 feb. 2018. Disponível em: <http://www.bbc. com/future/story/20180220-the-nation-that-thrived-by-nudging-its-population>. Acesso em: 5 maio 2018.

25 KEATING, Sarah. The nation that thrived by nudging its population. BBC, 20 feb. 2018. Disponível em: <http://www.bbc. com/future/story/20180220-the-nation-that-thrived-by-nudging-its-population>. Acesso em: 5 maio 2018. 


\section{NudgeS E DOAÇões de ÓRGÃOS PARA tRANSPLANTES}

"A teoria é a mesma que a das pensões: no fundo, a maioria das pessoas quer ser doadora se morrer em um acidente e seus órgãos poderiam ser usados para salvar a vida de outra pessoa, mas por várias razões nunca chegam a se registrar." ${ }^{26}$ Isso porque muitos dos sistemas para obtenção de órgãos é o do consentimento expresso.

Dois são os sistemas para obtenção de órgãos de doadores falecidos para transplantes, segundo a Organização Mundial de Saúde - OMS. O primeiro é o sistema de consentimento expresso (opting in / contracting in). Dependendo da legislação nacional, esse consentimento pode efetuar-se verbalmente ou ser registrado em um cartão de doador, na carteira nacional de habilitação, em documento de identidade, no histórico médico ou em um registro de doadores. Por meio desse sistema, o falecido deve ter manifestado expressamente antes de morrer a autorização para a extração de seus órgãos. Em caso de não ter deixado nenhuma declaração, a autorização é prestada por um familiar, que pode se negar a doar. O segundo sistema é o do consentimento presumido (opting out / contracting out). Diante deste, podem-se extrair órgãos do corpo da pessoa falecida, para fins de transplante, a menos que esta tenha manifestado em vida sua oposição ou que alguém declare que o falecido se opunha.

No Brasil, adota-se o consentimento expresso, mas a decisão sobre a doação pertence aos familiares do potencial doador. Assim, mesmo diante da manifestação em vida do falecido, a família pode recusar-se a permitir a extração. Houve, com a Lei n ${ }^{\circ} 9.434$ de 1997, uma tentativa de alteração para o consentimento presumido, ${ }^{27}$ de forma a gravar-se a expressão "não doador de órgãos e tecidos" em documento de identificação caso se optasse por não ser doador. Entretanto, o consentimento expresso voltou a ser exigido a partir de uma medida provisória logo convertida na Lei nº 10.211 de 2001.

Portanto, a retirada de órgãos de pessoas falecidas para transplantes ou outra finalidade terapêutica depende, no país, da autorização do cônjuge ou parente firmada em documento subscrito por duas testemunhas presentes à verificação da morte. Em relação às doações intervivos, quando envolverem qualquer pessoa a não ser cônjuge ou parente consanguíneo até o quarto grau, estas devem ser objeto de autorização judicial.

A Alemanha, também, tentou, sem sucesso, em 1978 e em 1997,28 adotar o sistema presumido. No país, a pessoa somente se torna um doador se optar, explicitamente, pelo sistema assinando um cartão de doador de órgãos. ${ }^{29}$ Mas, desde 2012, os alemães, com mais de 16 anos de idade, serão solicitados ao menos uma vez durante sua vida a decidir se querem doar. ${ }^{30}$ A lei determina, ainda, que empresas de seguro médico informem regularmente a seus clientes sobre a doação de órgãos. ${ }^{31}$

Ao menos quatro estados americanos, Connecticut, Texas, Colorado e Pensilvânia, também consideraram alterar sua legislação, sem êxito. Isso porque, nos Estados Unidos, os americanos são contrários ao

$26 \mathrm{CHU}$, Ben. What is 'nudge theory' and why should we care? Explaining Richard Thaler's Nobel economics prize-winning concept. Independent, 9 oct. 2017. Disponível em: <https://www.independent.co.uk/news/business/analysis-and-features/nudge-theory-richard-thaler-meaning-explanation-what-is-it-nobel-economics-prize-winner-2017-a7990461.html>. Acesso em: 5 maio 2018.

27 Em sentido diverso ao que era estabelecido pela Lei no 5.479 de 1968.

28 DEN BÜRGERN reinen Wein einschenken. Süddeutsche Zeitung, Munique, 6 märz. 2018. Disponível em: < http://www.sueddeutsche.de/kolumne/organspende-den-buergern-reinen-wein-einschenken-1.3894155>. Acesso em: 27 mar. 2018.

29 ORGAN SCANDAL forces rethink of donor system. DW, 6 ago. 2012. Disponível em: < http://www.dw.com/en/organscandal-forces-rethink-of-donor-system/a-16146350>. Acesso em: 24 mar. 2018.

30 GERMAN patients turn to Croatia for organ donations. DW, 29 jan. 2018. Disponível em: <http://www.dw.com/en/germanpatients-turn-to-croatia-for-organ-donations/a-42357468>. Acesso em: 24 mar. 2018; ORGAN TRANSPLANT scandal shocks Germany. DW, 21 jul. 2012. Disponível em: <http://www.dw.com/en/organ-transplant-scandal-shocks-germany/a-16116631>. Acesso em: 25 mar. 2018.

31 GERMANY lags behind in organ donations. DW, 4 jan. 2013. Disponível em: <http://www.dw.com/en/germany-lagsbehind-in-organ-donations/a-16498057>. Acesso em: 24 mar. 2018. 
controle do Estado sobre seus corpos. Os direitos individuais, no país, são muito importantes. ${ }^{32}$

Israel, Áustria, ${ }^{33}$ Espanha, Bélgica, Colômbia, França e Holanda adotam o sistema de presunção ou de exclusão. O Reino Unido pretende alterar seu sistema opt in para opt out. ${ }^{34}$

$\mathrm{Na}$ Colômbia, em agosto de 2016, foi sancionada uma lei que torna obrigatória a doação de órgãos no país, exceto nos casos em que as pessoas manifestem em vida o contrário. Eliminou-se a exigência da autorização dos familiares, que eram aqueles que decidiam sobre a doação de órgãos do falecido. ${ }^{35}$

A França adaptou sua legislação a partir de $1^{\circ}$ de janeiro de $2017^{36}$ para regular o princípio do consentimento presumido, ${ }^{37} \mathrm{em}$ vigor no país desde 1976. Presume-se que todos os adultos franceses consentem na remoção de seus órgãos após a morte, a menos que, durante sua vida, tenham expressado uma recusa. ${ }^{38}$ Acredita-se que a taxa de recusas diminua considerando-se uma "melhor informação e conscientização pública e, especialmente, na qualidade do treinamento de profissionais de saúde que entrevistam famílias após a morte de um ente querido." 39

A lei holandesa de fevereiro de 2018 estabeleceu o registro de todos os cidadãos com mais de 18 anos como um doador de órgãos em potencial, a menos que, explicitamente, se oponham. Todos os adultos que ainda não se registraram como doadores de órgãos receberão duas cartas pedindo-lhes que indiquem sua opção. Se eles não responderem após o segundo e-mail, serão automaticamente adicionados à lista, embora possam corrigir seu status a qualquer momento. Diante das dificuldades quando da aprovação do projeto de lei, uma alteração foi inserida, e a família será consultada e dará a decisão final. ${ }^{40}$

Pode-se preferir um sistema de doações de órgãos a serem recusadas. Isso levaria as pessoas a registrarem-se. ${ }^{41}$

32 SAMUEL, Leah. To solve organ shortage, states consider 'opt-out' organ donation laws. Stat News, 6 jul. 2017. Disponível em: <https://www.statnews.com/2017/07/06/opt-solution-organ-shortage/>. Acesso em: 24 mar. 2018.

33 A Áustria tem um sistema no qual as pessoas devem se opor explicitamente a uma doação. GERMANY lags behind in organ donations. DW, 4 jan. 2013. Disponível em: <http://www.dw.com/en/germany-lags-behind-in-organ-donations/a-16498057>. Acesso em: 24 mar. 2018.

34 THERESA May's shift towards presumed-consent organ donation praised by charities and patients. Independent, 5 oct. 2017. Disponível em: <https://www.independent.co.uk/news/uk/politics/theresa-may-organ-donation-policy-praised-transplants-presumed-consent-opt-out-system-conservative-a7984021.html>. Acesso em: 6 maio 2018.

35 COLÔMBIA torna obrigatória a doação de órgãos. Terra, 8 ago. 2016. Disponível em: < https://www.terra.com.br/vida-eestilo/saude/colombia-torna-obrigatoria-a-doacao-de-orgaos,b71ddf2d3c7e71918d945694d75c00cel5rg5lo2.html>. Acesso em: 29 mar. 2018.

36 A PARTIRDU1erjanvier, tous les Français seront donneurs d'organes par défaut. Lexpress, 29 dec. 2016. Disponível em: < https:// www.lexpress.fr/actualite/societe/sante/a-partir-du-1er-janvier-tous-les-francais-seront-donneurs-d-organes-par-defaut_1864325. html?utm_campaign=Echobox\&utm_medium=Social\&utm_source $=$ Facebook\&link_time $=1483015812 \# x$ tor $=$ CS3-5076>. Acesso em: 7 maio 2018.

37 BENJAMIN, Anna. Don d'organe: “Les prélèvements ne seront pas automatiques". Lexpress, 30 dec. 2016. Disponível em: <https://www.lexpress.fr/actualite/societe/sante/don-d-organe-les-prelevements-ne-seront-pas-automatiques_1864548.html>. Acesso em: 7 maio 2018; NEW DUTCH law makes every adult an organ donor. DW, 14 feb. 2018. Disponível em: <http://www. dw.com/en/new-dutch-law-makes-every-adult-an-organ-donor/a-42576784>. Acesso em: 24 mar. 2018.

38 Uma pessoa poderá expressar sua recusa por meio de três possibilidades: cadastro eletrônico no Registro Nacional de Recusa; documento datado e assinado atestando a oposição; e informação oral prestada a um ente querido sobre a oposição. Com a morte, este terá que transcrever a recusa por escrito, mencionando precisamente o contexto e as circunstâncias de sua expressão. A remoção de órgãos não é automática após a morte; acontece quando não tenha havido recusa claramente expressada.

39 BENJAMIN, Anna. Don d'organe: "Les prélèvements ne seront pas automatiques". Lexpress, 30 dec. 2016. Disponível em: <https://www.lexpress.fr/actualite/societe/sante/don-d-organe-les-prelevements-ne-seront-pas-automatiques_1864548.html>. Acesso em: 7 maio 2018.

40 DEN BÜRGERN reinen Wein einschenken. Süddeutsche Zeitung, Munique, 6 märz. 2018. Disponível em: <http://www. sueddeutsche.de/kolumne/organspende-den-buergern-reinen-wein-einschenken-1.3894155>. Acesso em: 27 mar. 2018; NEW DUTCH law makes every adult an organ donor. DW, 14 feb. 2018. Disponível em: < http://www.dw.com/en/new-dutch-lawmakes-every-adult-an-organ-donor/a-42576784>. Acesso em: 24 mar. 2018.

$41 \mathrm{CHU}, \mathrm{Ben}$. What is 'nudge theory' and why should we care? Explaining Richard Thaler's Nobel economics prize-winning concept. Independent, 9 oct. 2017. Disponível em: <https://www.independent.co.uk/news/business/analysis-and-features/nudge-theory-richard-thaler-meaning-explanation-what-is-it-nobel-economics-prize-winner-2017-a7990461.html>. Acesso em: 5 maio 2018. 
Em Illinois, nos Estados Unidos, existe a chamada "escolha obrigatória". Desde 2006, quando o cidadão vai renovar sua carteira de motorista e atualizar sua fotografia, deve responder se deseja ser um doador de órgãos. Este sistema vincula juridicamente os desejos da pessoa de ser doadora, independentemente da vontade ou da oposição de familiares. ${ }^{42}$

Mas, embora bem-intencionada, a adoção do sistema presumido poderia reduzir, e não aumentar, o número de doações. ${ }^{43}$

Para Benjamin, a lei não deve surgir como expressão de uma política agressiva, correndo o risco de ter o efeito oposto. A colheita de órgãos deve, sempre, aparecer como expressão altruísta um ato de generosidade após a morte. ${ }^{44}$ Métodos pesados de influência poderiam reduzir a motivação intrínseca de uma pessoa para se comportar da maneira desejada ou mesmo levar a um desafio de oposição. Os nudges evitariam esses efeitos adversos.

Israel tem um programa para engajar voluntários, ${ }^{45}$ combinando a alocação de órgãos com incentivos. ${ }^{46}$ Em 2008, aprovou-se no país uma legislação que prevê pagamentos do governo para assistência médica de um doador e perdas monetárias relacionadas, bem como autorizou-se o Ministério da Saúde a "dar status preferencial nas listas de espera de transplante para doadores registrados e aqueles que consentiram na doação de um parente." (tradução nossa) ${ }^{47}$

Isso porque "todo transplante economiza um quarto de milhão de dólares nos primeiros cinco anos. Custa US $\$ 90.000$ por ano para fazer diálise, US $\$ 100.000$ para o transplante e US $\$ 20.000$ por ano para medicamentos antirrejeição." 48 (Tradução nossa).

Em que pese a medula óssea não ser um órgão, em 30 de abril de 2018, por meio da Lei Federal n ${ }^{\circ}$ 13.656, o Brasil passou a isentar do pagamento de taxa de inscrição em concursos federais (para provimento de cargo efetivo ou emprego permanente em órgãos ou entidades da administração pública direta e indireta da União) candidatos doadores de medula óssea em entidades reconhecidas pelo Ministério da Saúde.

No estado do Acre, desde 2015, uma lei concede isenção do pagamento da inscrição em concursos públicos para provimento de cargos ou empregos públicos estaduais a candidatos que forem doadores de sangue ou de medula óssea. ${ }^{49}$

\section{Política e políticas públicas}

Diferencia-se a política das políticas públicas. Política é um conceito geral; políticas públicas são assuntos políticos específicos.

42 THALER, Richard H. Opting in vs. Opting out. The New York Times, 26 sep. 2009. Disponível em: <https://www.nytimes. com/2009/09/27/business/economy/27view.html>. Acesso em: 24 mar. 2018. Ver ainda em: <http://www.donatelifeillinois. $\operatorname{org} />$.

43 SAMUEL, Leah. To solve organ shortage, states consider 'opt-out' organ donation laws. Stat News, 6 jul. 2017. Disponível em: <https://www.statnews.com/2017/07/06/opt-solution-organ-shortage/>. Acesso em: 24 mar. 2018.

44 BENJAMIN, Anna. Don d'organe: “Les prélèvements ne seront pas automatiques". Lexpress, 30 dec. 2016. Disponível em: <https://www.lexpress.fr/actualite/societe/sante/don-d-organe-les-prelevements-ne-seront-pas-automatiques_1864548.html>. Acesso em: 7 maio 2018.

45 INSIDE the world of kidney trafficking. The New York Times, 20 aug. 2014. Disponível em: < https://www.nytimes. com/2014/08/21/opinion/inside-the-world-of-kidney-trafficking.html>. Acesso em: 29 mar. 2018.

46 TRUOG, Robert; SEGAL, Brad. Options for increasing the supply of transplantable organs. Harvard Health Policy Review, 2 dec. 2017. Disponível em: <http://bioethics.hms.harvard.edu/news/ethical-constraints-organ-rationing>. Acesso em: 24 mar. 2018.

47 SACK, Kevin. A clash of religion and bioethics complicates organ donation in Israel. The New York. Times, 17 aug. 2014. Disponível em: <https://www.nytimes.com/2014/08/17/world/middleeast/a-clash-of-religion-and-bioethics-complicates-organdonation-in-israel.html>. Acesso em: 4 abr. 2018.

48 SHUTE, Nancy. How an economist helped patients find the right kidney donors. NPR, 11 june 2015. Disponível em: <https://www.npr.org/sections/health-shots/2015/06/11/412224854/how-an-economist-helped-patients-find-the-right-kidney-donor>. Acesso em: 29 mar. 2018.

49 A Lei inicialmente promulgada foi a de $n^{\circ} 2.973$ de 22 de julho de 2015, revogada e substituída pela Lei Complementar nº 345 de 15 de março de 2018. 
A política pode ser entendida como a busca por estabelecer políticas públicas, mas pode existir política sem propostas de políticas públicas.

Diante dos muitos aspectos do conceito de política, três grandes divisões foram estabelecidas: o sistema jurídico e a estrutura institucional político-administrativa (polity), os processos políticos de tomada de decisão (politics) e a congregação de ambos — as políticas públicas (policy). ${ }^{50}$

A primeira dificuldade com a qual se defronta a análise das políticas públicas é o caráter polissêmico do termo "política". As coisas são mais simples para os autores de língua inglesa, pois eles dispõem de termos diferentes para designar o que o francês reúne sob a noção de política. Com efeito, este termo cobre, ao mesmo tempo, a esfera da política (polity), a atividade política (politics) e a ação pública (policies). A primeira faz a distinção entre o mundo da política e a sociedade civil, podendo a fronteira entre os dois, sempre fluida, variar segundo os lugares e as épocas; a segunda designa a atividade política em geral (a competição pela obtenção dos cargos políticos, o debate partidário, as diversas formas de mobilização...); a terceira acepção, enfim, designa o processo pelo qual são elaborados e implementados programas de ação pública, isto é, dispositivos político-administrativos coordenados em princípio em torno de objetivos explícitos. ${ }^{51}$

Nesse contexto, trata-se a política pública de um "fluxo de decisões públicas, orientado a manter o equilíbrio social ou a introduzir desequilíbrios destinados a modificar essa realidade", um sistema de decisões públicas "destinadas a manter ou modificar a realidade de um ou vários setores da vida social, por meio da definição de objetivos e estratégias de atuação e da alocação dos recursos necessários para atingir os objetivos estabelecidos". ${ }^{52}$ É "a coordenação dos meios à disposição do Estado, harmonizando as atividades estatais e privadas para a realização de objetivos socialmente relevantes e politicamente determinados". ${ }^{53}$

Lowi, partindo da força coercitiva de cada uma das políticas públicas, classifica-as em distributivas, regulatórias, redistributivas e constitutivas. Políticas Públicas Distributivas geram maior impacto individual que universal, compreendendo decisões que privilegiam grupos específicos. Políticas Públicas Redistributivas deslocam recursos de uma camada social para outra impondo perdas concretas para certos grupos sociais. Políticas Públicas Regulatórias estabelecem regras, criando normas para a implementação das políticas distributivas e redistributivas. Por fim, as Políticas Públicas Constitutivas, que estruturam processos e procedimentos: ampliando ou diminuindo a autoridade governamental, alterando o exercício dos direitos dos indivíduos, ampliando ou restringindo as opções de ação. ${ }^{54}$

A política pública constitui um processo formado de etapas que, embora nem sempre se separem ou se sucedam, influenciam-se.

A primeira etapa trata-se da "percepção e definição de problemas", sendo que nem todas as necessidades alcançam sua inclusão como assunto público prioritário do governo.

Somente na próxima etapa, relativa à "inclusão da agenda", decide-se se o tema será efetivamente inserido na pauta política. "Para poder tomar essa decisão, é preciso pelo menos uma avaliação preliminar sobre custos e benefícios das várias opções disponíveis de ação, assim como uma avaliação das chances do tema

50 SCHMIDT, João Pedro. Para entender as políticas públicas: aspectos conceituais e metodológicos. In: REIS, Jorge Renato dos; LEAL, Rogério Gesta. (Org.). Direitos sociais e politicas públicas: desafios contemporâneos. Santa Cruz do Sul: EDUNISC, 2008. t. 8. p. 2307-2333. Disponível em: <http://www.mp.go.gov.br/portalweb/hp/10/docs/para_entender_as_politicas_publicas_-_aspectos_conceituais_e_metodologicos.pdf $>$. Acesso em: 4 maio 2013.

51 MULLER, Pierre; SUREL, Yves. A análise das políticas públicas. Pelotas: Educat, 2002. p. 10.

52 SARAVIA, Enrique. Introdução à teoria da política pública. In: SARAVIA, Enrique; FERRAREZI, Elisabete (Org.). Politicas públicas: coletânea. Brasília: ENAP, 2006. v. 1. p. 28-29. Disponível em: <http://www.enap.gov.br/index.php?option=com_ docman\&task $=$ cat_view\&gid $=858>$. Acesso em: 21 jun. 2013.

53 BUCCI, Maria Paula Dallari. Políticas públicas e direito administrativo. Revista de Informação Legislativa, Brasília, v. 34, n. 133, jan./mar. 1997. p. 91.

54 LOWI, Theodore J. Four systems of policy, politics, and choice. Public Administration Review, v. 32, n. 4, p. 298-310, jul./ago. 1972. Disponível em: <http://www.platonicmedia.co.uk/wp-content/uploads/2011/02/Lowi_1972PAR.pdf>. Acesso em: 1 jun. 2013. 
ou projeto de se impor na arena política." ${ }^{55}$

Trata-se da inserção de determinada necessidade ou pleito na lista de prioridades do poder público, transformando-o em objeto de debates e de controvérsias políticas. ${ }^{56}$

Mas nem todas as necessidades transformam-se em demandas, requer-se um processo de politização ou articulação de vontades.

Posteriormente, a terceira etapa, a da elaboração ou "preparação da decisão política": a identificação e delimitação de um problema e possíveis alternativas de solução.

Já a "formulação" inclui a seleção da alternativa entendida como mais conveniente. Constitui a decisão política tomada e a sua formalização por meio de uma norma jurídica.

Uma boa formulação da ação governamental resulta na "implantação", que é a colocação em prática da decisão. É a realização da política, o conjunto de ações destinado a concretizar os objetivos estabelecidos.

O "acompanhamento" consiste no processo de supervisão da execução com objetivo de fornecer informações para eventuais correções necessárias, ${ }^{57}$ enquanto a "avaliação" constitui a mensuração e análise dos resultados produzidos — julga os impactos da política pública na sociedade.

Nessa fase de avaliação e de correção de ação, apreciam-se os impactos efetivos dos programas implementados. "Trata-se de indagar os déficits de impacto e os efeitos colaterais indesejados para poder deduzir consequências para ações e programas futuros.” Alcançados os objetivos, pode-se suspender ou encerrar o ciclo, ou, caso contrário, modificar ou iniciar um novo programa. ${ }^{58} \mathrm{~A}$ adequada valoração da política nessa fase é muito importante porque justifica a preferência por um ou outro programa, servindo de base para posteriores. ${ }^{59}$

No que pertine à otimização de todo o ciclo de políticas públicas,

Nos últimos anos, o governo brasileiro vem investindo na discussão e aprovação de diversas normas para intensificar o uso dos benefícios trazidos pelas tecnologias com o objetivo de otimizar todo o ciclo de políticas públicas. As recentes alterações normativas incluem a nova identificação civil nacional (ICN), a obrigatoriedade da coleta de dados biométricos dos cidadãos, a interoperabilidade entre as bases de dados, a integração dos dados civis (SIRC), a integração dos dados de registro de imóveis (SINTER), a nota fiscal eletrônica de serviços, entre outros. $\mathrm{O}$ aproveitamento da tecnologia nas funções de governo associa-se à discussão sobre a proteção de direitos. Em relação aos projetos de lei em andamento, destacam-se os projetos para estabelecer marco regulatório do uso e proteção dos dados pessoais e sobre valor probante de documentos digitais. ${ }^{60}$

De qualquer modo, "para assegurar a igualdade, importa não apenas garantir a inclusão digital, mas também a educação, a fim de que os debates sejam travados com consciência política, transparência e honesti-

55 FREY, Klaus. Políticas públicas: um debate conceitual e reflexões referentes à prática da análise de políticas públicas no Brasil. Planejamento e Politicas Públicas, n. 21, jun. 2000. p. 227.

56 SARAVIA, Enrique. Introdução à teoria da política pública. In: SARAVIA, Enrique; FERRAREZI, Elisabete (Org.). Políticas públicas: coletânea. Brasília: ENAP, 2006. v. 1. p. 28-29. Disponível em: < http://www.enap.gov.br/index.php?option=com_ docman\&task $=$ cat_view\&gid $=858>$. Acesso em: 21 jun. 2013.

57 SARAVIA, Enrique. Introdução à teoria da política pública. In: SARAIVA, Enrique; FERRAREZI, Elisabete (Org.). Políticas públicas: coletânea. Brasília: ENAP, 2006. v. 1. p. 28-29. Disponível em: <http://www.enap.gov.br/index.php?option=com_ docman\&task $=$ cat_view\&gid $=858>$. Acesso em: 21 jun. 2013.

58 FREY, Klaus. Políticas públicas: um debate conceitual e reflexões referentes à prática da análise de políticas públicas no Brasil. Planejamento e Politicas Públicas, n. 21, jun. 2000.

59 FIGUEIREDO, Marcus Faria; FIGUEIREDO, Argelina M. Cheibub. Avaliação política e avaliação de políticas: um quadro de referência teórica. Análise e Conjuntura, Belo Horizonte, v. 1, n. 3, p. 107-127, set./dez. 1986. Disponível em: <http://www.ssc.wisc. edu/ jmuniz/AC-2007-38.pdf>. Acesso em: 23 jun. 2013.

60 VARELLA, Marcelo D.; OLIVEIRA, Clarice G.; MOESCH, Frederico. Salto digital nas políticas públicas: oportunidades e desafios. Revista Brasileira de Políticas Públicas, v. 7, n. 3, p. 561-584, 2017. Disponível em: < https://publicacoes.uniceub.br/RBPP/ article/view/4808>. Acesso em: 4 jul. 2018. 
dade, devendo-se observar normas quanto ao diálogo". ${ }^{61}$

Por fim, a existência dos direitos sociais decorre do surgimento das políticas públicas, que "repercutem na economia e nas sociedades, daí por que qualquer teoria da política pública precisa também explicar as inter-relações entre Estado, política, economia e sociedade." ${ }^{\prime 2}$

\section{Considerações finais}

Em que pese a importância da utilização econômica dos nudges, estes coexistem em outros campos a não ser o exclusivamente econômico, e a doação de órgãos é um exemplo de uma área em que os nudges merecem ser mais estudados e trabalhados.

Nesse sentido, solicitar aos cidadãos, em mais de uma oportunidade, se gostariam de ser doadores; informá-los regularmente sobre a doação de órgãos para transplante; lembrá-los da importância dos cuidados preventivos no combate a causas de insuficiência de órgãos; enviar-lhes correspondências indicando o incremento nas doações.

Essas são algumas das possibilidades indicadas.

Uma outra alternativa de política pública - e que não exclui as anteriores, é o sistema opt-out, por meio do qual todos os brasileiros seriam automaticamente registrados como doadores de órgãos, a menos que decidissem indicar o contrário. Esse sistema é diferente do opt-in, em que os doadores têm de optar.

Estudos a respeito fazem-se necessários à medida que a população envelhece e a pressão por ampliar a oferta de órgãos intensifica-se.

Impõe-se a inclusão na agenda e a formulação e implantação de políticas públicas eficazes para a redução da escassez de órgãos humanos para transplantes.

Como resultado do trabalho, sugere-se, dentre outras ferramentas, a doação presumida de órgãos como um nudge a incrementar o número de doadores.

Como consequência dos resultados, conclui-se que nudges podem ser utilizados como política pública para aumentar o número de doadores de órgãos humanos para transplantação no Brasil.

Com o presente artigo, pretende-se contribuir para a retomada da discussão sobre o tema e a consequente implementação de políticas públicas com o objetivo de aumentar o número de doadores para transplantes.

Portanto, seu resultado tem implicações práticas, sociais e econômicas, uma vez que os transplantes salvam vidas além de reduzir o custo com saúde.

\section{REFERÊNCIAS}

A PARTIR DU 1er janvier, tous les Français seront donneurs d'organes par défaut. Lexpress, 29 dec. 2016. Disponível em: <https://www.lexpress.fr/actualite/societe/sante/a-partir-du-1er-janvier-tousles-francais-seront-donneurs-d-organes-par-defaut_1864325.html?utm_campaign=Echobox\&utm_

61 MACHADO, Raquel Cavalcanti Ramos; RIVERA, Laura Nathalie Hernandez. Democratização na era digital: desafios para um diálogo consciente e igualitário. Revista Brasileira de Políticas Públicas, v. 7, n. 3, p. 602-617, 2017. Disponível em: <https://publicacoes.uniceub.br/RBPP/article/view/4801>. Acesso em: 4 jul. 2018.

62 SOUZA, Celina. Políticas públicas: uma revisão da literatura. Sociologias, Porto Alegre, ano 8, n. 16, p. 20-45, jul./dez. 2006. Disponível em: <http:// www.scielo.br/pdf/soc/n16/a03n16.pdf>. Acesso em: 4 jun. 2013. 
medium $=$ Social\&utm_source $=$ Facebook\&link_time $=1483015812 \#$ xtor $=C S 3-5076>$. Acesso em: 7 maio 2018.

ACRE. Lei Complementar no 345 de 15 de março de 2018. Disponível em: <http://www.al.ac.leg.br/leis/wpcontent/uploads/2018/03/LeiComp345-1.pdf>. Acesso em: 7 maio 2018.

BENJAMIN, Anna. Don d'organe: "Les prélèvements ne seront pas automatiques". Lexpress, 30 dec. 2016. Disponível em: <https://www.lexpress.fr/actualite/societe/sante/don-d-organe-les-prelevements-ne-seront-pas-automatiques_1864548.html>. Acesso em: 7 maio 2018.

BRASIL. Decreto no 9.175, de 18 de outubro 2017. Disponível em: <http://www.planalto.gov.br/ccivil_03/_ Ato2015-2018/2017/Decreto/D9175.htm\#art56>. Acesso em: 11 nov. 2017.

BRASIL. Lei $n^{\circ} 5.479$ de 10 de agosto de 1968. Disponível em: <http://www.planalto.gov.br/ccivil_03/ leis/1950-1969/L5479.htm>. Acesso em: 11 nov. 2017.

BRASIL. Lei $n^{\circ} 9.434$ de 4 de fevereiro de 1997. Disponível em: <http://www.planalto.gov.br/ccivil_03/leis/ L9434compilado.htm>. Acesso em: 11 nov. 2017.

BRASIL. Lei no 13.183, de 4 de novembro de 2015. Disponível em: < http://www.planalto.gov.br/ccivil_03/_ ato2015-2018/2015/lei/113183.htm>. Acesso em: 26 maio 2018.

BRASIL. Lei no 13.656, de 30 de abril de 2018. Disponível em: <http://www.planalto.gov.br/ccivil_03/_ Ato2015-2018/2018/Lei/L13656.htm>. Acesso em: 7 maio 2018.

BRASIL. Ministério da Saúde. Portaria $n^{0}$ 2.600, de 21 de outubro de 2009. Disponível em: <http://bvsms. saude.gov.br/bvs/saudelegis/gm/2009/prt2600_21_10_2009.html>. Acesso em: 13 abr. 2018.

BRASIL. Supremo Tribunal Federal. Ação Direta de Inconstitucionalidade (ADI) 5502, com pedido de liminar, impugnando dispositivos da Lei 12.618/2012, que instituiu o regime de previdência complementar para os servidores públicos federais titulares de cargo efetivo. Disponível em: <http://www.stf.jus.br/portal/processo/verProcessoAndamento.asp?incidente $=4967555>$. Acesso em: 26 maio 2018.

BUCCI, Maria Paula Dallari. Políticas públicas e direito administrativo. Revista de Informação Legislativa, Brasília, v. 34, n. 133, jan./mar. 1997.

CHINA to cease prisoner organ transplants. DW, 04 dez. 2014. Disponível em: <http://www.dw.com/en/ china-to-cease-prisoner-organ-transplants/a-18109346>. Acesso em: 10 fev. 2018.

CHU, Ben. What is 'nudge theory' and why should we care? Explaining Richard Thaler's Nobel economics prize-winning concept. Independent, 9 oct. 2017. Disponível em: <https://www.independent.co.uk/news/ business/analysis-and-features/nudge-theory-richard-thaler-meaning-explanation-what-is-it-nobel-economics-prize-winner-2017-a7990461.html>. Acesso em: 5 maio 2018.

CIOATTO, Roberta Marina; BOFF, Salete Oro. Concretização de direitos sociais por meio de políticas públicas: uma aproximação necessária. Rev. Fac. Direito UFMG, Belo Horizonte, n. 63, p. 575-613, jul./ dez. 2013. Disponível em: <https://www.direito.ufmg.br/revista/index.php/revista/article/view/P.03042340.2013v63p575/1447>. Acesso em: 3 jul. 2018.

CIOATTO, Roberta Marina; PINHEIRO, Adriana de Alencar Gomes. Transplantes de órgãos humanos no Brasil: a temática não pode ser declarada morta. Revista Direitos e Garantias Fundamentais, Vitória, v. 18, n. 3, 2017. Disponível em: <http://sisbib.emnuvens.com.br/direitosegarantias/article/view/1130/0>. Acesso em: 25 mar. 2018.

COLÔMBIA torna obrigatória a doaçãodeórgãos. Terra, 8 ago. 2016. Disponível em: $<$ https://www.terra.com. br/vida-e-estilo/saude/colombia-torna-obrigatoria-a-doacao-de-orgaos,b71ddf2d3c7e71918d945694d75c00cel5rg5lo2.html>. Acesso em: 29 mar. 2018. 
DEN BÜRGERN reinen Wein einschenken. Süddeutsche Zeitung, Munique, 6 märz. 2018. Disponível em: $\quad<$ http://www.sueddeutsche.de/kolumne/organspende-den-buergern-reinen-wein-einschenken-1.3894155>. Acesso em: 27 mar. 2018.

ELÉXITO de los trasplantes. ElPaís, 12 ene. 2018. Disponível em: < https:/ / elpais.com/elpais/2018/01/12/ opinion/1515782432_390027.html?id_externo_rsoc=TW_CC\&utm_content=buffer2c070\&utm_ medium=social\&utm_source=facebook.com\&utm_campaign=buffer $>$. Acesso em: 10 fev. 2018.

ESPANHA é campeã do mundo em doações de órgãos. Exame, 17 abr. 2017. Disponível em: <https:// exame.abril.com.br/ciencia/espanha-e-campea-do-mundo-em-doacoes-de-orgaos/>. Acesso em: 13 nov. 2017.

FAN, Jiayang. Can China stop organ trafficking? The New Yorker, 10 jan. 2014. Disponível em: < http://www. newyorker.com/news/news-desk/can-china-stop-organ-trafficking>. Acesso em: 1 maio 2017.

FIGUEIREDO, Marcus Faria; FIGUEIREDO, Argelina M. Cheibub. Avaliação política e avaliação de políticas: um quadro de referência teórica. Análise e Conjuntura, Belo Horizonte, v. 1, n. 3, p. 107-127, set./ dez. 1986. Disponível em: <http://www.ssc.wisc.edu/ jmuniz/AC-2007-38.pdf>. Acesso em: 23 jun. 2013.

FRAGA, Érica; PINTO, Ana Estela de Sousa. Escolas públicas de São Paulo usam teorias de Nobel para reduzir evasão. Folha de São Paulo, 15 out. 2017. Disponível em: <http://www1.folha.uol.com.br/ mercado/2017/10/1927050-escolas-publicas-de-sao-paulo-usam-teorias-de-nobel-para-reduzir-evasao. shtml>. Acesso em: 5 maio 2018.

FREY, Klaus. Políticas públicas: um debate conceitual e reflexões referentes à prática da análise de políticas públicas no Brasil. Planejamento e Políticas Públicas, n. 21, jun. 2000.

GERMAN patients turn to Croatia for organ donations. DW, 29 jan. 2018. Disponível em: < http://www. dw.com/en/german-patients-turn-to-croatia-for-organ-donations/a-42357468 > . Acesso em: 24 mar. 2018.

GERMANY lags behind in organ donations. DW, 4 jan. 2013. Disponível em: <http://www.dw.com/en/ germany-lags-behind-in-organ-donations/a-16498057>. Acesso em: 24 mar. 2018.

INSIDE the world of kidney trafficking. The New York Times, 20 aug. 2014. Disponível em: <https://www. nytimes.com/2014/08/21/opinion/inside-the-world-of-kidney-trafficking.html>. Acesso em: 29 mar. 2018.

KEATING, Sarah. The nation that thrived by nudging its population. BBC, 20 feb. 2018. Disponível em: $<$ http://www.bbc.com/future/story/20180220-the-nation-that-thrived-by-nudging-its-population $>$. Acesso em: 5 maio 2018 .

LOWI, Theodore J. Four systems of policy, politics, and choice. Public Administration Review, v. 32, n. 4, p. 298 310, jul./ago. 1972. Disponível em: <http://www.platonicmedia.co.uk/wp-content/uploads/2011/02/ Lowi_1972PAR.pdf>. Acesso em: 1 jun. 2013.

MACHADO, Raquel Cavalcanti Ramos; RIVERA, Laura Nathalie Hernandez. Democratização na era digital: desafios para um diálogo consciente e igualitário. Revista Brasileira de Políticas Públicas, v. 7, n. 3, p. 602-617, 2017. Disponível em: <https://publicacoes.uniceub.br/RBPP/article/view/4801>. Acesso em: 4 jul. 2018.

MULLER, Pierre; SUREL, Yves. A análise das políticas públicas. Pelotas: Educat, 2002.

NEW DUTCH law makes every adult an organ donor. DW, 14 feb. 2018. Disponível em: < http://www. dw.com/en/new-dutch-law-makes-every-adult-an-organ-donor/a-42576784>. Acesso em: 24 mar. 2018.

ORGAN SCANDAL forces rethink of donor system. DW, 6 ago. 2012. Disponível em: <http://www. dw.com/en/organ-scandal-forces-rethink-of-donor-system/a-16146350>. Acesso em: 24 mar. 2018.

ORGAN TRANSPLANT transplant scandal shocks Germany. DW, 21 jul. 2012. Disponível em: < http:// 
www.dw.com/en/organ-transplant-scandal-shocks-germany/a-16116631>. Acesso em: 25 mar. 2018.

OSSOLA, Alexandra. Crisis in America: medical experts use new tech tools to combat the organ transplant shortage. CNBC, 21 jun. 2017. Disponível em: <https://www.cnbc.com/2017/06/20/medical-expertsuse-new-tech-tools-to-combat-organ-transplant-shortage.html>. Acesso em: 24 mar. 2018.

ASSOCIAÇÃO BRASILEIRA DE TRANSPLANTE DE ÓRGÃOS. Dimensionamento dos Transplantes no Brasil e em cada estado (2010-2017). Registro Brasileiro de Transplantes, São Paulo, ano 23, n. 4, jan./dez. 2017. Disponível em: <http:/ www.abto.org.br/abtov03/default.aspx?mn $=515 \& \mathrm{c}=900 \& s=0 \&$ friendly $=\mathrm{re}$ gistro-brasileiro-de-transplantes-estatistica-de-transplantes>. Acesso em: 7 nov. 2017.

SACK, Kevin. A clash of religion and bioethics complicates organ donation in Israel. The New York Times, 17 aug. 2014. Disponível em: <https://www.nytimes.com/2014/08/17/world/middleeast/a-clash-of-religion-and-bioethics-complicates-organ-donation-in-israel.html>. Acesso em: 04 abr. 2018.

SAMUEL, Leah. To solve organ shortage, states consider 'opt-out' organ donation laws. Stat News, 6 jul. 2017. Disponível em: <https://www.statnews.com/2017/07/06/opt-solution-organ-shortage/>. Acesso em: 24 mar. 2018.

SARAVIA, Enrique. Introdução à teoria da política pública. In: SARAIVA, Enrique; FERRAREZI, Elisabete (Org.). Políticas públicas: coletânea. Brasília: ENAP, 2006. v. 1. p. 28-29. Disponível em: <http://www.enap. gov.br/index.php?option=com_docman\&task=cat_view\&gid=858>. Acesso em: 21 jun. 2013.

SCHMIDT, João Pedro. Para entender as políticas públicas: aspectos conceituais e metodológicos. In: REIS, Jorge Renato dos; LEAL, Rogério Gesta. (Org.). Direitos sociais e políticas públicas: desafios contemporâneos. Santa Cruz do Sul: EDUNISC, 2008. t. 8. p. 2307-2333. Disponível em: <http://www.mp.go.gov.br/portalweb/hp/10/docs/para_entender__as_politicas_publicas_-_aspectos_conceituais_e_metodologicos. pdf $>$. Acesso em: 4 maio 2013.

SHUTE, Nancy. How an economist helped patients find the right kidney donors. NPR, 11 june 2015. Disponível em: <https://www.npr.org/sections/health-shots/2015/06/11/412224854/how-an-economisthelped-patients-find-the-right-kidney-donor>. Acesso em: 29 mar. 2018.

SOUZA, Celina. Políticas públicas: uma revisão da literatura. Sociologias, Porto Alegre, ano 8, n. 16, p. 20-45, jul./dez. 2006. Disponível em: <http:// www.scielo.br/pdf/soc/n16/a03n16.pdf>. Acesso em: 4 jun. 2013.

SUNSTEIN, Cass R. Nudging: a very short guide. J. Consumer Pol'y, v. 37, n. 583, 2014. Disponível em: $<$ https://dash.harvard.edu/bitstream/handle/1/16205305/shortguide9_22.pdf? sequence=4>. Acesso em: 6 maio 2018.

TAMS, Carten. Small is beautiful: using gentle nudges to change organizations. Forbes, 22 feb. 2018. Disponível em: <https://www.forbes.com/sites/carstentams/2018/02/22/small-is-beautiful-using-gentlenudges-to-change-organizations/\#6fc50c8e 5a8d>. Acesso em: 5 maio 2018.

THALER, Richard H. Opting in vs. Opting out. The New York Times, 26 sep. 2009. Disponível em: < https:// www.nytimes.com/2009/09/27/business/economy/27view.html>. Acesso em: 24 mar. 2018.

THALER, Richard H. The power of nudges, for good and bad. The New York Times, 31 oct. 2015. Disponível em: <https://www.nytimes.com/2015/11/01/upshot/the-power-of-nudges-for-good-and-bad. html>. Acesso em: 5 maio 2018.

THALER, Richard H. etal. Governments are trying to nudge us into better behaviour: is it working? The Washington Post, 11 aug. 2017. Disponível em: <https://www.washingtonpost.com/news/wonk/wp/2017/08/11/ governments-are-trying-to-nudge-us-into-better-behavior-is-it-working/?noredirect=on\&utm_ term $=.104 \mathrm{c} 8 \mathrm{ff} 2655 \mathrm{a}>$. Acesso em: 5 maio 2018.

THERESA May's shift towards presumed-consent organ donation praised by charities and patients. Inde- 
pendent, 5 oct. 2017. Disponível em: < https://www.independent.co.uk/news/uk/politics/theresa-may-organ-donation-policy-praised-transplants-presumed-consent-opt-out-system-conservative-a 7984021 .html>. Acesso em: 6 maio 2018.

TRUOG, Robert; SEGAL, Brad. Options for increasing the supply of transplantable organs. Harvard Health Policy Review, 2 dec. 2017. Disponível em: < http://bioethics.hms.harvard.edu/news/ ethical-constraintsorgan-rationing $>$. Acesso em: 24 mar. 2018.

VARELLA, Marcelo D.; OLIVEIRA, Clarice G.; MOESCH, Frederico. Salto digital nas políticas públicas: oportunidades e desafios. Revista Brasileira de Políticas Públicas, v. 7, n. 3, p. 561-584, 2017. Disponível em: $<$ https://publicacoes.uniceub.br/RBPP/article/view/4808>. Acesso em: 4 jul. 2018.

WER NICHT widerspricht, wird Organspender. Süddeutsche Zeitung, Munique, 13 feb. 2018. Disponível em: $\quad<$ http://www.sueddeutsche.de/politik/niederlande-wer-nicht-widerspricht-wird-organspender-1.3866596>. Acesso em: 27 mar. 2018.

WORLD HEALTH ORGANIZATION. Global Observatory on Donation and Transplantation. Disponível em: $<$ http://www.transplant-observatory.org/summary/>. Acesso em: 10 nov. 2017.

WORLD HEALTH ORGANIZATION. WHA 63/22. Princípios Orientadores da OMS sobre transplante de células, tecidos y órgãos humanos aprovados pela 63ª Assembleia Mundial de Saúde, de maio de 2010. Disponível em: <http://www.who.int/transplantation/Guiding_PrinciplesTransplantation_WHA63.22sp. pdf?ua=1>. Acesso em: 12 nov. 2017. 
Para publicar na revista Brasileira de Políticas Públicas, acesse o endereço eletrônico www.rbpp.uniceub.br

Observe as normas de publicação, para facilitar e agilizar o trabalho de edição. 